linking system; and the economic dangers of moving from an unlimited use, print-based model, to recurring, license-based fee structures. That the most enduring of these discussions consist principally of warnings seems to point out that there are still a number of basic problems dating from the inception of the digital library yet to be solved.

Perhaps the most developed and still relevant theme that crosses multiple essays relates to the changing nature of scholarly communication and intellectual property rights. A number of essays mention the promise of the Internet to provide open access to scholarly material and predict the rise of preprint and institutional repositories. Some of these essays also point out the problems that are faced when attempting to apply print-based copyright law to digital material, where the line between content and process is often blurred.

Following two sections of essays focusing principally on predictions and emerging patterns in the digital library realm, the collection concludes with a number of papers focusing on emerging and successful projects, such as the Internet Public Library, distance learning initiatives, and digital collections of government documents. Although interesting as historical documents, as a whole these papers have little other value today, as they simply describe projects that have either been completed or superseded, or that have progressed well beyond their state at time of presentation.

When taken as a whole, this collection clearly demonstrates the value of the Kanazawa Institute of Technology's series of International Roundtables as a forward-thinking gathering of pioneers in the digital library world. That many of these essays remain at least somewhat relevant is truly an accomplishment. That said, the value of this work is hindered by its overall lack of timeliness and the fact that many of these authors have gone on to reprise and refine their views of the still-developing digital library.-James M Jackson Sanborn(james_sanborn@ncsu.edu), North Carolina State University Libraries, Raleigh.

The Title-Page: Its Early Development, 1460-1510. By Margaret M. Smith. New Castle, Del.: Oak Knoll Pr., 2000. 160p. $\$ 39.95$ (ISBN 1-58456-033-9)

The first work of such specific focus since Alfred W. Pollard's 1891 Last Words on the History of the Title Page, Margaret M. Smith's brief monograph sets out to take a new look at its subject from the post-Elisabeth Eisenstein field of book history. In addition to being something of an update of its centenarian predecessor, Smith's work complements other studies, fitting neatly from a chronological standpoint between Pollard's An Essay on Colophons (1905) and works covering later periods, including A. F. Johnson's German Renaissance Titleborders (1929) and M. Corbett and R.W. Lightbown's The Comely Frontispiece 1979. Unlike especially this last work and the more recent Chronus und Historia (1995) by Margery Kintzinger, which take more iconographic approaches, Smith smartly appears to be more concerned with establishing organic genres of titlepage design. One should begin reading this book with the very brief final chapter, titled "Conclusions," but truly more of an abstract. Here, Smith most clearly summarizes the current picture of the title-page's evolution, a story of competing styles, false starts, and a finally dominant form. In fact, nonincunabulists may wish to stop reading here, as Smith's work follows in the intellectual tradition of The Printing Press As an Agent of Change but lacks its eye-opening freshness. The strength of the earlier chapters comes in textual and graphic presentations, in chronological perspective, of the fruitful results of Smith's quantitative sampling (although, oddly, Smith avoids address- ing geographical factors in such strong fashion, leaving open questions of how significant were regional differences in the title-page's early development). While overall this new work doesn't offer much in the way of new insights, it does provide an important and longneglected evidentiary foundation that supports many commonly held ideas of the title-page's development._Darby Orcutt (darby_orcutt@ncsu.edu), North Carolina State University Libraries, Raleigh

\section{Introduction to Technical} Services. By G. Edward Evans, Sheila S. Intner, and Jean Weihs. 7th ed. Greenwood Village, Colo.: Libraries Unlimited, 2002. 543 p. paper $\$ 49.50$ (ISBN 156308-922-X)

Cataloging and Classification for Library Technicians. By Mary Liu Kao. 2d ed. New York: Haworth, 2001. 146p. cloth $\$ 39.95$ (ISBN 0-7890-1062-3); paper $\$ 19.95$ (ISBN 0-7890-1063-1)

The first through fifth editions of the classic Introduction to Technical Services were titled Introduction to Technical Services for Library Technicians. The change in title reflects the changing need for training in technical services, even for the professional librarian. Schools of library (or information) science are minimally training their students in cataloging (and that even is not a required course for most) and might touch on other aspects of technical services generically. But, for the most part, there appears to be a misconception that knowledge of processing, acquiring, and organizing materials is either no longer necessary or can be picked up on the job. As readers of Library Resources of Technical Services are well aware, the skills are necessary, and there are rarely staff left who can pass on the knowledge through in-service training. Introduction to Technical Services can fill this gap. It can also be used as a textbook for either master's-level 
library school courses or for library technical assistant courses.

The book is divided into three large sections: general background, acquisitions and serials, and cataloging and processing. Individual chapters present both theoretical discussions of topics and basic applications of fundamental processes. Extensive readings are supplied, as are review questions. This edition also introduces Canadian practice in most chapters, although the discussion is abbreviated. I particularly liked the numerous examples of records, screens shots, forms, and so on sprinkled throughout the text and was even more impressed by the separate index to the examples.

The writing is lively, interesting, and sparked with humor. For example, "acquisitions departments are the ultimate recipients of unsolicited gifts ... (sometimes accompanied by a variety of molds and insects)" (165). Although there are three authors, and most likely each author worked on separate sections, the book reads as though one person wrote it.

Any book that attempts to cover all of technical services in just 543 pages cannot cover every aspect in depth, but I do wish a few areas had been given more attention. In the acquisitions section for example, there is no discussion of the ethical aspects of commercial transactions. Should the librarian accept gifts from vendors? Should the functions of ordering, receiving, and paying be separated? Electronic resource acquisitions (serial and nonserial) would benefit from more discussion of the need for negotiating licenses (with and without legal counsel). There is very little about the process of requesting bids (for an approval vendor, a new library management system, or outsourcing). And there is no discussion of the possibility that systems maintenance may be a part of technical services. All of these functions may not be the purview of the library technical assistant, but given the direction that many libraries are going (see opening paragraph of this review), they very well could be. Overall, however, this is an excellent summary of the world of technical services. I wouldn't hesitate to give it to any of my staff members (in my previous supervisory life) to fill in the gaps in their knowledge.

On the other hand, Cataloging and Classification for Library Technicians is meant to be used as a textbook for a course in copy cataloging, and I would suggest using it only with close supervision and supplementing it with lectures by a knowledgeable instructor. In only 146 pages, Kao covers much the same ground as Evans, Intner, and Weihs cover in the last 201 pages of their book. There are far fewer theoretical discussions, as is appropriate for the audience.

The second edition differs from the first in that there are many more examples and some of the more egregious errors have been corrected (for example, in the first edition, the Library of Congress Subject Headings are stated as being in the sixteenth edition on page 18 and as being in the seventeenth edition on page 65). A new chapter, "Cataloging on Computers," covers the MARC format (only a definition is given in the first edition) and a brief overview of searching on OCLC. Kao gives a very broad workflow for searching and edition a record.

Like the Introduction to Technical Services, Cataloging and Classification for Library Technicians has review questions at the end of each chapter. There is also a glossary at the beginning of each chapter. Some chapters start with this list; some chapters have an introduction first. I found this inconsistency in layout annoying; there didn't appear to be any reason for it.

Kao is best when she sticks to broad strokes; when she strives for detail, she falls into error. In the descriptive cataloging chapter, she discusses each chapter of the second edition of the Anglo-American Cataloguing Rules separately: in discussing chapter twelve (formerly titled "Serials," but now "Continuing Resources') she states "If titles of different issues vary, use "Title varies" (43). The serials cataloger in me knows this is dead wrong.

Despite its shortcomings, there is no other book devoted exclusively to copy cataloging for support staff, and this edition shows improvement over the first edition. I would, however, have a warning label on the book: "Not to be used without an instructor present."-Marguerite E. (Maggie) Horn, (maggie.horn@suny.edu), State University of New York, System Administration, Office of Library and Information Services 